\title{
A Study of Interest Areas of High School Students in Relation to Some Socio-Psycho Variables
}

\author{
Prof. Veenaben Patel ${ }^{1}$, Dr. H.B. Patel ${ }^{2}$, Ms. Hema. G ${ }^{3} *$
}

\section{ABSTRACT}

The best way of selecting one's career is to select according to his/her own interest areas. This right choice of career can be done only by giving awareness of the interested areas. If the student is aware of the interest areas of his/her own, the selection of career can be made effective and useful to achieve the desired goal of life. It also provides a platform for further progress in his/her life. Consequently, such selection will save time, money and energy of the students. This type of study will also benefit to the parents also. The awareness of the parents on their children's area of interest can enable them to guide their children in the selection of their career. Instead of forcing the students to take their higher studies, knowledge about their children's career will in advance help in the selection of career. The pursuit of higher education has been promoted by parents and the government, at least in part in response to the expectation that India is transforming from a resource-based to a knowledge-based economy, in which most future occupations will require some kind of postsecondary credential. As a central construct of career development, career exploration involves activities that attempt to relate knowledge of oneself to the external world and the internal world structures) and can be described as an openness to experience that fosters self discovery and prompts reflection about environmental action.

Keywords: Areas of interest, vocational interest, High school students, psycho-social variables

The main focus of all schools of philosophy, the educationists, the sociologist, the institutes, and the teachers is on the overall development of a student for balanced and a progressive society. The proportionate growth and development of the student is essential in order to create good human being. Even the pages of any good book of sociology also ponder on the student and the society. A student has his fundamental right to grow according to his personality, aptitude and interest as the systematic development of a student is the universally accepted goal of education. There are many other factors that affect the growth and development of a student. Whenever an academic progress of a student is discussed, the matters of progress of a student that are based on various factors in life that affect his development cannot be avoided. As today's world is

\footnotetext{
${ }^{1}$ Dean \& Principal, Faculty of Education, Kadi SarvaVishwavidyalaya, Gandhinagar, Gujarat

${ }^{2}$ Principal, Grow More College of Education, Himmatnagar, Gujarat

${ }^{3}$ Asst Professor, R.H. Patel English Medium, B.Ed College, Kadi SarvaVishwavidyalaya, Gandhinagar, Gujarat *Responding Author

(C) 2016 I V Patel, H Patel, Hema G; licensee IJIP. This is an Open Access Research distributed under the terms of the Creative Commons Attribution License (http://creativecommons.org/licenses/by/2.0), which permits unrestricted use, distribution, and reproduction in any Medium, provided the original work is properly cited.
} 
growing fast, an element of competition and also of growth, progress and development are felt everywhere. The teachers in the schools are engaged and anxious to provide better experience and maximum opportunities to a student. Even the parents are anxious for their ward's future. In the present formal educational system, a student enters in the system under the impression of their guardians. The guardians have no vision for the opportunities ahead. Proper guidance and counselling system at any stage of education has not been set up yet. Thus, a student enters in the system by external forces. At every stage, the student becomes a victim of those external forces of parents and society. The chances have never been provided to him to think about his future. Consequently, he always remains under stress. The student is also under mental stress for his career or future profession. In such situations it is a quite a difficult task for the teachers, the parents and the students to select right career or course. A student's career selected on the basis of either his friend's choice or his parents' force or keeping in mind only the present trends of society. If a student's career is directed on the basis of the above mentioned and some other factors, there are less chances of success in life resulting in frustration in his life. On account of such situation his time, money and energy is wasted. Such type of wastage is neither beneficial to a society, to nation, to parents, to teachers nor to a student even.

After the S.S.C exam, a student has various options like arts, commerce, science, vocational courses, etc. to be selected. When a student has various types of courses or discipline available, he is tempted to join any of the courses without taking in consideration his area of interest, aptitude, mental ability, personality, etc. It is commonly observed that many of them joining different faculties or disciplines do not have clear perception of the future of the path that is to be selected or the usefulness of the study. Illiterate or half-educated friends who are senior to them by a year or two are not matured enough to guide such type of students. A proper and wellorganized provision of systematic guidance programme for the students on the basis of their interests to join one of these different faculties. Owing to absence of such a scientific guidance programme in the field of education, many square pegs are put in round holes. In India, the educational institutes are turn into the factories producing number of young unemployed boys and girls who do not pace with their respective field and ultimately they are frustrated.

The knowledge of the areas of the interest keeps the student, the parents, the teachers, a society or even nation to select and to direct a student's career on a proper path. Even the counselors can utilize the knowledge of the areas of interest in counseling works. So keeping in view the abovementioned facts the investigator thought it fit to investigate the areas of interest of the high schools students of Sabarkantha district in the context of some psycho-socio variables.

\section{Concept of Interest}

The task of defining and giving the meaning of any term in any field of study is quite a difficult one as different persons from different perspectives view the term. The above said statement is also applicable to the term of interest. Rigorous efforts have been made by the psychologists to define the term interest. The term interest is very complex in nature. Those who have studied the 
nature of interest tried to put the nature of interest in their own words. The simple notion of interest is a sense of attachment or attraction towards a particular object or lesson. Everyone possesses some type of interest to which he/she has some liking. He always gives preference to that particular object. These likings may be permanent or temporary depending on the attitudes and aptitudes. As Crow and Crow stated "Interest may refer to the motivating force that implies us to attend to a person, a thing or an activity, or it may be effective experience that has been stimulated by the activity itself”. In other words interest can be the cause of an activity and result of participation in that activity.

D. Fryer (1931) writes in "The Sense of Measurement "subjective interests are likes or dislikes which are estimated experiences, characterized by feeling of pleasantness or unpleasantness.”

The concept of vocational interest is defined from the notion of interest itself. The vocational interest is a person's likes and dislikes towards a particular profession, job or vocation. The individual performs most of his vocational activities because of his interest in that vocation, while he avoids doing those vocations in which he has no interest. When he is sometimes forced by circumstances into performing certain profession or vocation that does not interest him, it is done as a matter of formality. Vocational interest is a tendency, which motivates the individual to engage in a particular vocational activity. The individual tries to perform that activity under any circumstances, which interests him, and for that reason, he employs all his mental and physical powers in its performances. For example, if as individual is interested in music, he is more likely to be successful in music. Vocational interest is an indeterminate indicator of success in a particular area of vocation, profession or job.

The complexity of interest is indicated by historical surveys and the need for objective definitions is pointed out while the earlier conceptions of interest brought out the feeling aspect involved in interest. The cognitive aspect in explaining the term is emphasized by McDougall. He further explains that interest being essentially cognitive, is a matter of enduring the setting of our cognitive tendencies or impulses. Instincts and sentiments are thought to be the determinants of interest. The Hormic School of psychology has emphasized the conative aspect and described interest to be active and projective thus, both the conative and cognitive factors appear to comprise interest as a complex whole. Interest is thus a word with different shades of meaning.

\section{IMPORTANCE OF THE STUDY}

The common confusion that is felt by each student is what to do next, which faculty or discipline will prove to be lucrative. The parents of a student also face the same question. At present proper guidance to a student or to a parent is not available. The selection of career is made vaguely. The best way of selecting career is that a person should select it according to his own areas of interest. A right career or subject can be selected if the student is made aware of his area of interest. Such practice can make the selection effective and fruitful to achieve the desired goal of life. It provides him platform for further progress in his or her life. Consequently, such selection 
will save time, money and energy of the students. This type of study will be useful to the parents too. The familiarity of the parents with the areas of interest can enable them to guide their children in the selection of the courses or careers. They can think of their children's career well in advance and not just under the forces of others' ideas. The awareness of such study will make the teacher to guide their students in the selection of different disciplines. The teacher can also nurture the interests of the students. The teaching schedule can also be arranged in accordance with the general interest areas of the students.

As far as the counsellors are concerned, they can get the best possible result if they have knowledge of such study. The counsellors can guide the pupils for future selection of courses or the subjects. Even the counsellors can update themselves with the help of such studies.

From the point of view of the schools, it is also useful as the school can guide the students for their future life. The school can provide various options to the students in the subject selection. The school can arrange the schedule of the school and the co-curricular activities keeping in mind the areas of interest of the students.

The society is to be considered as an integral part of education. The interest of the students can be developed or nourished with the help of the society. With the help of such study, the authority may be familiar with the trends of areas of interest of the students. They can introduce new policies in education or introduce some changes in the curriculum in the light of such study.

The final goal of any education system is to provide well-planned human resources to the nation for its balanced progress. This study will help the system and nation for producing needed and molded human resources for the development of the nation.

\section{OBJECTIVES}

The following objectives were kept in mind in order to carry out the study

1. To investigate the areas of interest of the high school students.

2. To compare the areas of interest of the high school students in the context of their gender.

3. To compare the areas of interest of the high school students in the context of their residential area.

4. To compare the areas of interest of the high school students in the context of levels of their Achievement Level.

5. To compare the areas of interest of the high school students in the context of levels of their I.Q 


\section{Hypotheses}

The first objective of this present study was to investigate the areas of interest of the high school students so formulation of Ho was not possible for this objective.

Ho1 There is no significant effect of gender of high school students on the various areas of vocational interest.

Ho2 There is no significant effect of residential area of high school students on the various areas of vocational interest.

Ho3 There is no significant effect of achievement of high school students on the various areas of vocational interest.

Ho4 There is no significant effect of IQ of high school students on the various areas of vocational interest.

\section{Delimitations of the Study}

The limitations and delimitations of the present study were following.

1. The present study was delimited only to Sabarkantha district.

2. The present study was delimited only to Gujarati Medium schools of Sabarkantha district.

3. The students studying in the 9th and 8th standard were considered as the high school students.

\section{Operational Definitions of Key Terms}

Interest: Interests are the activities for which a person has a liking or disliking and for which he goes towards or away from, or a liking or disliking state of mind accompanying the doing of an activity or thought of performing the activity. These activities or thought are with special reference to different vocations. Therefore, interest is here meant vocational interest.

Interest Areas: The present study is concerned, the patterns of interests of students as are ascertained by an interest inventory standardized by the investigator are considered as interest areas. It is also written as area of interest or interest area. Vocational interest area is known as interest area for the present study.

High school students: The schools which provide instruction from VIII to X standard and recognized as high schools by the Department of Education of the state. The students studying in such type of schools are known as the high school students.

Socio-psycho variables: Dr Sharma in “The Dictionary of Educational Terms” writes, “The factors that are, generally, studied under the caption of sociology, are considered as socio factors." From the definition, it becomes clear that society, class, caste, creed, religion, economic status, social status, etc are the factors that are studied in sociology.

In the present study, the investigator studied the effect of sex and residential area as the socio variables. 
Psychology is an ever-expanding behavioral science. Many aspects are included in psychological study. There aspects are related to behavior, brain, environment or interaction effect of all these. In the present study, the effect of the psychological variable like I.Q. was studied.

\section{Variables}

The variables included in the present study were as given below:

\section{Independent Variables:}

1. Gender - Male and Female

2. Area of Residence - Urban and Rural

3. Level of Achievement- Low and High academic Achievement

4. Level of IQ-Low and High IQ

Dependent Variable: Areas of interest of high school students

\section{Research Method}

In the present study the characteristics and nature of the problem itself lead the investigator to select the normative survey research design. By using the survey research design the investigator tried to analyze the existing areas of interest in the context of some socio-psycho variables.

\section{Population and Sample}

The students studying in the Gujarati medium Schools of Sabarkantha district was the population. The investigator of the present study selected the samples from the Gujarati medium schools of Sabarkantha district. Stratified sampling technique was used in the present study.

The Gujarati Medium High schools of Sabarkantha districts were divided into two areas: Sabarkantha (Urban) and Sabarkantha (Rural).

All the 13 Talukas covered under Sabarkantha District were given consideration in the selection of sample. All the male and female students of the selected schools were the final samples of the present study.

Formation of Equivalent Groups for the study:

1. All samples of the study were divided according to the score of IQ

2. Median of all the samples was calculated and it was 106.Those samples that had the score less than 106 were considered as Low IQ level students. Those samples that had the score more than 106 were considered as High IQ level students.

3. The students having low IQ and high IQ were further divided according to their level of achievement.

4. The students are further divided according to their residential area: Rural and Urban

5. The samples were further divided according to their gender: Male and female

6. The samples in different strata are shown in the following table. 
Table 1: Classification of Sample in Different Strata

\begin{tabular}{|c|c|c|c|c|}
\hline IQ & Achievement & Residential Area & Gender & Total \\
\hline High IQ-402 & High Achiever & \multirow{4}{*}{$\begin{array}{c}\text { Urban } \\
1339\end{array}$} & \multirow{8}{*}{$\begin{array}{l}\text { Male } \\
3572\end{array}$} & \multirow{16}{*}{6444} \\
\hline Low IQ-271 & & & & \\
\hline High IQ-395 & \multirow{2}{*}{$\begin{array}{l}\text { Low Achiever } \\
666 \\
\end{array}$} & & & \\
\hline Low IQ-271 & & & & \\
\hline High IQ-580 & \multirow{2}{*}{$\begin{array}{l}\text { High Achiever } \\
974\end{array}$} & \multirow{4}{*}{$\begin{array}{l}\text { Rural } \\
2233\end{array}$} & & \\
\hline Low IQ-394 & & & & \\
\hline High IQ-757 & \multirow{2}{*}{$\begin{array}{l}\text { Low Achiever } \\
1259\end{array}$} & & & \\
\hline Low IQ-502 & & & & \\
\hline High IQ-379 & \multirow{2}{*}{\begin{tabular}{|l} 
High Achiever \\
622 \\
\end{tabular}} & \multirow{4}{*}{$\begin{array}{l}\text { Urban } \\
1141\end{array}$} & \multirow{8}{*}{ Female } & \\
\hline Low IQ-243 & & & & \\
\hline High IQ-306 & Low Achiever & & & \\
\hline Low IQ-213 & 519 & & & \\
\hline High IQ-506 & High Achiever & \multirow{4}{*}{$\begin{array}{l}\text { Rural } \\
1731\end{array}$} & & \\
\hline Low IQ-316 & 822 & & & \\
\hline High IQ-522 & \multirow{2}{*}{$\begin{array}{l}\text { Low Achiever } \\
909\end{array}$} & & & \\
\hline Low IQ-387 & & & & \\
\hline
\end{tabular}

\section{Research Tool}

The objectives of the present study required the following tools:-

1. A data sheet for demographical variables

2. Interest Inventory Standardized by the Investigator

3. Non-verbal I.Q. Test by Dr. Tarulata Shah

1. A data sheet for demographical variables: In the present study, there were some demographical variables. So a data sheet for demographical variable was constructed by the investigator. The samples were given a data sheet for demographical variable like name, date of birth, area of residence, gender and achievement score.

\section{Interest Inventory Standardized by the Investigator}

The Interest inventory was standardized by following the standard procedure as follows: Collection of Primary Information; Structure of Interest Inventory, Pre -Primary Testing, Expert Opinion, Primary Testing, Item Analysis, Standardized Test, Administration of Test and Calculation of Score of Test.

The following interest areas were identified while structuring the interest inventory:

R. Realistic-Outdoors, technical, mechanical, interests.

I. Investigative-Scientific, Inquiring, analytical interests.

A. Artistic-Dramatic, musical, self-expressive interests.

S. Social-Helping, guiding, group-oriented interests.

E. Enterprising-Entrepreneurial, Persuasive, Political, interests.

C. Conventional- Methodical, organized, clerical interests. 
The reliability and validity of the Interest inventory was also found.

The reliability of the tool was calculated by two methods: Split-Half Method and Method of Rational Equivalence.

Table 2: The interest area wise correlation for split-half method

\begin{tabular}{|l|l|l|l|l|l|l|}
\hline $\begin{array}{l}\text { Interest } \\
\text { Areas }\end{array}$ & Realistic & Investigative & Artistic & Social & Enterprising & Conventional \\
\hline $\begin{array}{l}\text { Correlation } \\
\text { between } \\
\text { split test }\end{array}$ & 0.75 & 0.72 & 0.69 & 0.63 & 0.67 & 0.54 \\
\hline Whole test & 0.86 & 0.83 & 0.82 & 0.77 & 0.80 & 0.70 \\
\hline
\end{tabular}

The rii is calculated by using the formula of KR20 for Rational Equivalence. It was found to be as below.

Table 3: The interest area wise correlation for Rational Equivalence method

\begin{tabular}{|l|l|l|l|l|l|l|}
\hline $\begin{array}{l}\text { Interest } \\
\text { Areas }\end{array}$ & Realistic & Investigative & Artistic & Social & Enterprising & Conventional \\
\hline rii & 0.71 & 0.62 & 0.58 & 0.53 & 0.64 & 0.50 \\
\hline
\end{tabular}

Validity is calculated in the following way: Content validity and concurrent validity

The content validity was calculated by taking expert opinion while the concurrent validity was calculated by comparing the score of Interest Inventory by Dr V V Chaudhary. The validity index is 0.89 .

\section{Data Collection}

The Investigator took pain in chalking out a detailed schedule for the administration of tools and the work was carried out accordingly. Some schools provided a special sitting arrangement whereas in other schools the work was carried out in the classrooms. The principals of the schools arranged for one or two teachers to assist in the administration of the tools. The students were informed about the work to be carried out. Ethical values play a vital role in research so the assurance was given to the students was that the personal data and score obtained on the test and inventory would be used only for research purpose and their future would not be affected by their obtained scores on the tests or inventory taken by them.

\section{Demographical variables}

In the beginning, a data sheet for the demographical variables was given to the students. The students were asked and guided to write their name, date of birth, sex and area of the residence in the sheet.

\section{Standardized Interest Inventory}

After a break of five minutes, the response sheets for form of Interest Inventory was distributed in the classroom and the students were told to fill in the details only. The Interest Inventory was now distributed to students in which total 159 statements were written. The students were guided 
how to give responses with the help of an example that was given in the inventory. There was no specific time limit so the students were given approximately 80 minutes to give the response as they were supposed to put encircle mark on appropriate response choice that we have discussed previously. The filled in response sheets of form were collected. The students were given 30 minutes break for relaxation.

\section{IQ Test}

Non-Verbal IQ test by Tarulata Shah was administered after 30 minutes break.

Non-Verbal IQ Test was then distributed to students in which total non- verbal type of questions were given. The students were guided how to give responses with the help of six examples those were given in the test. The students were given approximate time of 60 minutes to give the response as they were supposed to encircle appropriate response-A, B, C, D and E. The filled in response sheets were collected. It becomes easy for the investigator as the students were to give responses in separate responses sheet for form of VII, form of VII and non -Verbal IQ test.

\section{Data Analysis and Interpretation}

After collecting the data, the investigator scored as per the guideline given in the manuals. After the work of scoring the sheets, student wise cards were prepared in which score of different areas, IQ score, sex , level of achievement and residential area of students were shown. On the basis of such cards the investigator chalked out a data analyses plan and thought it worthwhile to computerize the data. The investigator of the present study considered four main variables and invoked an appropriate technique. There were four main variables having different levels in each so $2 \times 2 \times 2 x 2$ factorial design was formulated. After the treatment, the ANOVA was calculated to determine whether the means of two random samples were too different to attribute to chance or sampling error. ' $F$ ' test was conducted. The investigator found .01 and .05 levels more suitable in order to compare the variables. The calculations were carried out with the help of SPSS and cross verified by MS Excel.

\section{DATA ANALYSES FOR OBJECTIVE-1}

In the present study the researcher tried to investigate the areas of interest of the high school students and also study these areas of interests in the context of gender, residential area, levels of achievement and levels of IQ. Vocational Interest Inventory standardized by the researcher and Non- Verbal IQ Test by Dr Tarulata Shah were used to make an inquiry taking four independent variables. In this regard a systematic approach was adopted to standardize the tool for the study. Different six vocational areas were designed that covered a variety of vocation. These areas are named as realistic, investigative, artistic, social, enterprising, and conventional. The following table 4 shows the mean values of the area of interest based on the variables selected for the study. 
A Study of Interest Areas of High School Students in Relation to Some Socio-Psycho Variables

Table 4: The mean values of the area of interest based on the variables

\begin{tabular}{|l|l|l|l|l|l|l|l|l|}
\hline $\begin{array}{l}\text { Vocational } \\
\text { Area }\end{array}$ & Gender & Mean & $\begin{array}{l}\text { Residential } \\
\text { Area }\end{array}$ & Mean & Achievement & Mean & IQ & Mean \\
\hline \multirow{4}{*}{ Artistic } & Female & 72.42 & Rural & 71.16 & Low & 70.22 & Low & 71.77 \\
\cline { 2 - 9 } & Male & 70.09 & Urban & 71.06 & High & 72.11 & High & 70.70 \\
\hline \multirow{4}{*}{ Investigative } & Female & 45.82 & Rural & 47.60 & Low & 47.94 & Low & 47.94 \\
\cline { 2 - 9 } & Male & 49.50 & Urban & 48.28 & High & 47.78 & High & 47.84 \\
\hline \multirow{3}{*}{ Realistic } & Female & 51.15 & Rural & 50.42 & Low & 50.26 & Low & 50.41 \\
\cline { 2 - 9 } & Male & 49.88 & Urban & 50.49 & High & 50.64 & High & 50.47 \\
\cline { 2 - 9 } Social & Female & 83.06 & Rural & 84.71 & Low & 84.82 & Low & 84.90 \\
\hline \multirow{3}{*}{ Conventional } & 86.52 & Urban & 85.41 & High & 85.14 & High & 85.03 \\
\cline { 2 - 9 } & Female & 66.98 & Rural & 66.80 & Low & 66.80 & Low & 66.65 \\
\cline { 2 - 9 } & Male & 66.93 & Urban & 67.19 & High & 67.12 & High & 67.16 \\
\hline
\end{tabular}

From the table 4, looking into the mean scores, Artistic, Enterprising and Conventional vocational areas were found to be higher in female students as compared to male students, whereas, Investigative and Realistic areas were found to have higher mean scores in male students as compared to female students. From this we can conclude that female students were more interested in Artistic, Enterprising and Conventional vocational areas and male students were more interested in Investigative and Realistic areas. Further, Social area was found to be similar between both the genders.

In the context of residential area, rural students were found to have higher mean scores in Artistic and Conventional areas, whereas, the urban students were found to have higher mean scores in Investigative, Enterprising, Realistic and Social vocational areas. From this we can conclude that rural students were more interested in Artistic and Conventional areas and urban students were more interested in Investigative, Enterprising, Realistic and Social vocational areas. The mean scores of all the vocational areas were found to be higher in high achievement level students compared with the lower achievement level of students. Artistic, Investigative and Realistic areas were found to have higher mean scores in low IQ group of students, whereas, Enterprising, Social and Conventional areas were found to have higher mean scores in high IQ group of students. 


\section{DATA ANALYSES FOR OBJECTIVE-2}

The researcher has tried to present the mean, S.D. and $\mathrm{N}$ for gender in the context to various vocational interest areas in the table -5 .

Table-5 Descriptive Statistics for Gender

\begin{tabular}{|l|l|l|l|l|}
\hline Interest Areas & Gender & Mean & S.D & N \\
\hline Artistic & Female & 72.42 & 10.13 & 2872 \\
\cline { 2 - 5 } & Male & 70.09 & 9.54 & 3572 \\
\cline { 2 - 5 } & Total & 71.13 & 9.88 & 6444 \\
\hline \multirow{5}{*}{ Envestigative } & Female & 45.82 & 6.58 & 2872 \\
\cline { 2 - 5 } & Male & 49.50 & 6.26 & 3572 \\
\cline { 2 - 5 } & Total & 47.86 & 6.66 & 6444 \\
\hline \multirow{5}{*}{ Realistic } & Female & 51.15 & 7.34 & 2872 \\
\cline { 2 - 5 } & Male & 49.88 & 7.54 & 3572 \\
\cline { 2 - 5 } & Total & 50.45 & 7.48 & 6444 \\
\hline Social & Female & 83.06 & 10.50 & 2872 \\
\cline { 2 - 5 } & Male & 86.52 & 10.44 & 3572 \\
\cline { 2 - 5 } & Total & 84.98 & 10.61 & 6444 \\
\hline \multirow{5}{*}{ Conventional } & Female & 66.98 & 8.85 & 2872 \\
\cline { 2 - 5 } & Male & 66.93 & 8.72 & 3572 \\
\cline { 2 - 5 } & Total & 66.95 & 8.78 & 6444 \\
\hline & Female & 38.26 & 5.89 & 2872 \\
\cline { 2 - 5 } & Male & 35.36 & 5.54 & 3572 \\
\cline { 2 - 5 } & Total & 36.65 & 5444 \\
\hline
\end{tabular}

In the following table-6, the F value, significance value and remarks at .05 and .01 level is presented for the variable gender in the context of various vocational interest areas.

Table- 6 Tests of Between-Subjects Effects for Gender

\begin{tabular}{|l|l|l|l|l|}
\hline Independent Variable & Dependent Variable & F - value & Significance & Remarks \\
\hline \multirow{5}{*}{ Gender } & Artistic & 90.07 & 0.00 & $* *$ \\
\cline { 2 - 5 } & Investigative & 524.67 & 0.00 & $* *$ \\
\cline { 2 - 5 } & Enterprising & 46.00 & 0.00 & $* *$ \\
\cline { 2 - 5 } & Realistic & 174.47 & 0.00 & $* *$ \\
\cline { 2 - 5 } & Social & 0.04 & 0.84 & \\
\cline { 2 - 5 } & Conventional & 409.98 & 0.00 & $* *$ \\
\hline
\end{tabular}

\section{Significant at *05 level Significant at **01}

It is observed from the above table -6 that, the calculated value of $\mathrm{F}$ of female and male students of high school students for the areas of interest: Artistic, Investigative, Enterprising, realistic and Conventional are 90.07, 524.67, 46.00, 174.47 and 409.98 respectively at .01 level. It is concluded that there is significant effect of gender of high school students on the areas of 
interest: Artistic, Investigative, Enterprising, realistic and Conventional. The gender of high school students does not affect the areas of interest: Social. The mean score of female is 72.42 whereas for male is 70.09. It means that the female students are more interested in vocational interest area of Artistic than the male students.

\section{DATA ANALYSES FOR OBJECTIVE-3}

The researcher has tried to present the mean, S.D. and $\mathrm{N}$ for residential areas of students in the context to various vocational interest areas in the table -7 .

Table-7 Descriptive Statistics for Residential Area

\begin{tabular}{|l|l|l|l|l|}
\hline Interest Areas & Area & Mean & S.D & N \\
\hline \multirow{5}{*}{ Artistic } & Rural & 71.16 & 9.99 & 3964 \\
\cline { 2 - 5 } & Urban & 71.06 & 9.70 & 2480 \\
\cline { 2 - 5 } & Total & 71.13 & 9.88 & 6444 \\
\hline \multirow{5}{*}{ Enterprising } & Rural & 47.60 & 6.54 & 3964 \\
\cline { 2 - 5 } & Urban & 48.28 & 6.82 & 2480 \\
\cline { 2 - 5 } & Total & 47.86 & 6.66 & 6444 \\
\hline \multirow{5}{*}{ Realistic } & Rural & 50.42 & 7.56 & 3964 \\
\cline { 2 - 5 } & Urban & 50.49 & 7.35 & 2480 \\
\cline { 2 - 5 } & Total & 50.45 & 7.48 & 6444 \\
\hline \multirow{5}{*}{ Social } & Rural & 84.71 & 10.60 & 3964 \\
\cline { 2 - 5 } & Urban & 85.41 & 10.61 & 2480 \\
\cline { 2 - 5 } & Total & 84.98 & 10.61 & 6444 \\
\hline & Rural & 66.80 & 8.72 & 3964 \\
\cline { 2 - 5 } & Urban & 67.19 & 8.87 & 2480 \\
\cline { 2 - 5 } & Total & 66.95 & 8.78 & 6444 \\
\hline & Rural & 36.71 & 5.88 & 3964 \\
\cline { 2 - 5 } & Urban & 36.56 & 5.87 & 2480 \\
\cline { 2 - 5 } & Total & 36.65 & 5.88 & 6444 \\
\hline
\end{tabular}

In the following table-8, the $\mathrm{F}$ value, significance value and remarks at .05 and .01 level is presented for the variable residential area of students in the context of various vocational interest areas.

Table-8 Tests of Between-Subjects Effects for Residential Area

\begin{tabular}{|l|l|l|l|l|}
\hline Independent Variable & Dependent Variable & F - value & Significance & Remarks \\
\hline \multirow{5}{*}{ Residential Area } & Artistic & 0.16 & 0.69 & \\
\cline { 2 - 5 } & Investigative & 16.03 & 0.00 & $* *$ \\
\cline { 2 - 5 } & Enterprising & 0.13 & 0.72 & \\
\cline { 2 - 5 } & Realistic & 6.66 & 0.01 & $* *$ \\
\cline { 2 - 5 } & Social & 3.04 & 0.08 & $* *$ \\
\cline { 2 - 5 } & Conventional & 1.01 & 0.32 & $*$ \\
\hline
\end{tabular}

\section{Significant at *05 level Significant at **01}

It is observed from the above table -8 that, the calculated value of $\mathrm{F}$ of rural and urban students of high school students for the areas of interest: Investigative, realistic, and Social are 16.03, 6.66 and 3.04 respectively at 01 level. It is observed from the above table -8 that, the calculated value 
of $\mathrm{F}$ of rural and urban students of high school students for the areas of interest: Conventional is 1.01 at 05 level. It is concluded that there is significant effect of residence of high school students on the area of interest: Conventional. It is concluded that there is significant effect of residential area of high school students on the areas of interest: Investigative, realistic and Social. The residential area of high school students does not affect the areas of interest: Artistic and Enterprising.

\section{DATA ANALYSES FOR OBJECTIVE-4}

The researcher has tried to present the mean, S.D. and $\mathrm{N}$ for level of achievement in the context to various vocational interest areas in the table -9 .

Table-9 Descriptive Statistics for Achievement

\begin{tabular}{|l|l|l|l|l|}
\hline Interest Areas & Achievement level & Mean & S.D & N \\
\hline \multirow{5}{*}{ Artistic } & Low & 70.22 & 9.78 & 3353 \\
\cline { 2 - 5 } & High & 72.11 & 9.89 & 3091 \\
\cline { 2 - 5 } & Total & 71.13 & 9.88 & 6444 \\
\hline \multirow{4}{*}{ Enterprising } & Low & 47.94 & 6.70 & 3353 \\
\cline { 2 - 5 } & High & 47.78 & 6.62 & 3091 \\
\cline { 2 - 5 } & Total & 47.86 & 6.66 & 6444 \\
\hline \multirow{5}{*}{ Realistic } & Low & 50.26 & 7.45 & 3353 \\
\cline { 2 - 5 } & High & 50.64 & 7.51 & 3091 \\
\cline { 2 - 5 } & Total & 50.45 & 7.48 & 6444 \\
\hline \multirow{4}{*}{ Social } & Low & 84.82 & 10.69 & 3353 \\
\cline { 2 - 5 } & High & 85.14 & 10.52 & 3091 \\
\cline { 2 - 5 } & Total & 84.98 & 10.61 & 6444 \\
\hline \multirow{4}{*}{ Conventional } & Low & 66.80 & 8.83 & 3353 \\
\cline { 2 - 5 } & High & 67.12 & 8.72 & 3091 \\
\cline { 2 - 5 } & Total & 66.95 & 8.78 & 6444 \\
\cline { 2 - 5 } & Low & 36.45 & 5.85 & 3353 \\
\cline { 2 - 5 } & High & 36.87 & 5.90 & 3091 \\
\cline { 2 - 5 } & Total & 36.65 & 5.88 & 6444 \\
\hline
\end{tabular}

In the following table-10, the $\mathrm{F}$ value, significance value and remarks at .05 and .01 level is presented for the variable level of Achievement in the context of various vocational interest areas.

Table-10 Tests of Between-Subjects Effects for Achievement

\begin{tabular}{|l|l|l|l|l|}
\hline Independent Variable & Dependent Variable & F - value & Significance & Remarks \\
\hline \multirow{4}{*}{ Achievement level } & Artistic & 59.95 & 0.00 & $* *$ \\
\cline { 2 - 6 } & Investigative & 0.93 & 0.34 & $*$ \\
\cline { 2 - 6 } & Enterprising & 4.06 & 0.04 & $* *$ \\
\cline { 2 - 6 } & Realistic & 1.48 & 0.23 & $*$ \\
\cline { 2 - 6 } & Social & 2.18 & 0.14 & $* *$ \\
\cline { 2 - 6 } & Conventional & 7.92 & 0.01 & $*$ \\
\hline
\end{tabular}

Significant at $* 05$ level Significant at $* * 01$

It is observed from the above table 10 that, the calculated value of $\mathrm{F}$ of high achievement level and low achievement level of students of high school for the areas of interest: Artistic, 
Enterprising and Social are 59.95, 4.06 and 2.18 respectively at 01 level. It is observed from the above table - that the calculated value of $\mathrm{F}$ of high achievement level and low achievement level of students of high school for the areas of interest: Investigative, realistic and Conventional are 0.93, 1.48 and 7.92 respectively at 05 level. It is concluded that there is significant effect of achievement level of high school students on the all areas of interest.

The mean score of low achievement level of students is 36.45 whereas for high achievement level of students is 36.87. It means that the low achievement level of students is more interested in vocational interest areas of Conventional than the high achievement level of students.

\section{DATA ANALYSES FOR OBJECTIVE-5 IQ}

The researcher has tried to present the mean, S.D. and N for level of IQ in the context to various vocational interest areas in the table -11 .

Table-11 Descriptive Statistics for IQ

\begin{tabular}{|l|l|l|l|l|}
\hline Interest Areas & IQ level & Mean & S.D & N \\
\hline \multirow{5}{*}{ Artistic } & Low IQ & 71.77 & 9.10 & 2597 \\
\cline { 2 - 5 } & High IQ & 70.70 & 9.77 & 3847 \\
\cline { 2 - 5 } & Total & 71.13 & 9.88 & 6444 \\
\hline \multirow{5}{*}{ Envestigative } & Low IQ & 47.90 & 6.66 & 2597 \\
\cline { 2 - 5 } & High IQ & 47.84 & 6.69 & 3847 \\
\cline { 2 - 5 } & Total & 47.87 & 6.66 & 6444 \\
\hline \multirow{5}{*}{ Realistic } & Low IQ & 50.41 & 7.59 & 2597 \\
\cline { 2 - 5 } & High IQ & 50.47 & 7.40 & 3847 \\
\cline { 2 - 5 } & Total & 50.45 & 7.48 & 6444 \\
\hline \multirow{5}{*}{ Social } & Low IQ & 84.90 & 10.63 & 2597 \\
\cline { 2 - 5 } & High IQ & 85.03 & 10.59 & 3847 \\
\cline { 2 - 5 } & Total & 84.98 & 10.61 & 6444 \\
\hline \multirow{5}{*}{ Conventional } & Low IQ & 66.65 & 8.81 & 2597 \\
\cline { 2 - 5 } & High IQ & 67.16 & 8.75 & 3847 \\
\cline { 2 - 5 } & Total & 66.95 & 8.78 & 6444 \\
\hline & Low IQ & 36.52 & 5.90 & 2597 \\
\cline { 2 - 5 } & High IQ & 36.74 & 5.86 & 3847 \\
\cline { 2 - 4 } & Total & 36.65 & 5.88 & 6444 \\
\hline
\end{tabular}

In the following table-12, the $\mathrm{F}$ value, significance value and remarks at .05 and .01 level is presented for the variable IQ in the context of various vocational interest areas. 
Table-12 Tests of Between-Subjects Effects for IQ

\begin{tabular}{|l|l|l|l|l|}
\hline Independent Variable & Dependent Variable & F - value & Significance & Remarks \\
\hline \multirow{5}{*}{ IQ Level } & Artistic & 18.49 & 0.00 & $* *$ \\
\cline { 2 - 6 } & Investigative & 0.11 & 0.74 & \\
\cline { 2 - 6 } & Enterprising & 0.11 & 0.74 & \\
\cline { 2 - 6 } & Realistic & 0.25 & 0.62 & \\
\cline { 2 - 5 } & Social & 5.08 & 0.02 & $* *$ \\
\cline { 2 - 5 } & Conventional & 2.25 & 0.13 & $*$ \\
\hline
\end{tabular}

Significant at *05 level Significant at **01

It is observed from the above table-12 that, the calculated value of F of Low IQ level and High IQ level of high school students for the areas of interest: Artistic and Social are 18.49 and 5.08 respectively at 01 level. It is observed from the above table - that the calculated value of $\mathrm{F}$ of Low IQ level and High IQ level of high school students for the area of interest: Conventional is 2.25 respectively at 05 level. It is concluded that there is significant effect of IQ level of high school students on the areas of interest: Artistic, Social and Conventional. The IQ level of high school students does not affect the areas of interest: Investigative, Enterprising and realistic.

\section{MAJOR FINDINGS}

After the intensive study on the areas of vocational interest in context of some socio-psycho variables, the following major findings have been drawn.

1. The gender, level of achievement and level of IQ play an important role in the selection of interest area of artistic whereas residential area has nothing to do with the interest area of artistic.

2. The gender, residential area and level of achievement play an important role in the selection of interest area of investigative work whereas level of IQ has nothing to do with the interest area of investigative work.

3. The residential area and level of IQ have nothing to do with the interest area of enterprising work whereas the gender and level of achievement play an important role in the selection of interest area of enterprising work.

4. The gender, residential area and level of achievement play an important role in the selection of interest area of realistic work whereas level of IQ has nothing to do with the interest area of realistic work.

5. The gender has nothing to do with the interest area of social work whereas the residential area, level of achievement and level of IQ play an important role in the selection of interest area of social work.

6. It's interesting to note down that all the variables: the gender, residential area, level of achievement and level of IQ play an important role in the selection of interest area of conventional work.

7. It's also an interesting observation that the areas of investigative work and realistic work are affected by the same variables of the gender, residential area and level of achievement and level of IQ whereas level of IQ has nothing to do with the interest both the areas of interest.

8. The level of IQ has its essential impact only on three interest areas: artistics, social and conventional work. 


\section{A Study of Interest Areas of High School Students in Relation to Some Socio-Psycho Variables}

9. The residential area of the students has its essential impact on four interest areas: investigative, realistic, social and conventional work.

10. The gender of students emerges as the most influential factor for all the interest areas where as IQ emerges as the least influential factor for all the interest areas.

\section{EDUCATIONAL IMPLICATIONS}

After a comprehensive study the above mentioned conclusions have been drawn out. On the basis of the conclusions emerged the following mentioned suggestions are to be made to the student teachers, parents, school, counsellors and society. They are hereby advised to follow the suggestions so that the energy of the students can be directed in a right way.

1. As it was observed from the research that the counselling session had great impact on the decision making of students in the selection of vocational areas so it is advised that there should be counsellor in each school. The role of counsellor should be to counsel for the selection of vocation

2. The other method of exhibition of various vocations should be organized in school level, cluster level, tensile level and district level.

3. Different movies and documentaries shows to be also arranged in order to raise the level of decision making of students at their school days.

4. There are many experts available in the practical field. The expertise of such expert also can be useful as their lectures are arranged in school.

\section{CONCLUSION}

The present study was conducted to know the vocational interest areas and its relationship with gender, residential area, achievement level and IQ level of high school students in Sabarkantha district in Gujarat. To the knowledge of the investigator, there were few researches conducted in India. Considering this fact, the researcher tried to find the knowledge that is useful in the field of education. This attempt of researcher will be considered useful if the findings of the study are used to improve the present scenario of the education system. On the whole, by creating the awareness of interest areas among students, parents and teachers, which helps in the right choice of career. Thus, further it helps for future citizens of the society, and consequently for the National development as whole. This study, have application for thousands of students, parents and educational stakeholders.

\section{REFERENCES}

Anne Anastasi(1957).Psychological Testing .First Edition, New York, Macmillan Pub.co.Page-49.

Anne Anastasi.(1988).Psychological Testing 6thEdition,NewYork, MacMillan Pub.,Co.Page-166.

Carter, H.D.(1940). The Development of Vocational Attitude . Journal of Consult. Psychology. p14.

Cattel, R.B.(1950).Personality, A Systematic Theoretical and Factual Study. NewYork: McGraw Hill.

Darley, J.G. and Theda Hegenah.(1955). Vocational Interest Measurement Theory and Practice. Minneapolis University. Minnesota Press.

Guilford, J.P.(1956).Fundamental Statistics in Psychology and Education. New York : MacGraw Hill Book Co. 
H.E Garrett.(1981).Statistic in Psychology and Education ,First Edition, Bombay,Vails,Feffer and Simons Ltd. 280

J. C. Aggrawal.(1966).Educational Research an Introduction. Arya Book Depo, NewDelhi,p. 60. J.P Guilford(1954).Psychometric Methods, New York, McGraw Hill Book Co.Page-379.

W.A Mahrens and J.J Lehmann.(1969).Standardized Tests in Education, NewYork, Halt ,Rinehart and Wintson,Inc .Page-42. 